\title{
Ruta chalepensis L. Essential Oil: A New Antisprouting Agent for Potatoes Bioconservation
}

\author{
Olfa Lengliz $\mathbb{D}$, ${ }^{1,2}$ Jamel Mejri, ${ }^{1}$ Manef Abderrabba, ${ }^{1}$ Rachid Khalifa, ${ }^{3}$ and Mondher Mejri ${ }^{4}$ \\ ${ }^{1}$ Laboratory of Materials, Molecules and Applications, IPEST, Road Sidi Bou Said, BP 51, La Marsa, Tunisia \\ ${ }^{2}$ University of Carthage, National Institute of Applied Science and Technology, BP 676, 1080 Tunis Cedex, Tunisia \\ ${ }^{3}$ Technical Center of Potato and Artichoke in Manouba, Street Jedaida Km17, Essaidia, Manouba, Tunisia \\ ${ }^{4}$ Higher Institute of Biotechnology of Beja, University of Jendouba, Avenue Habib Bourguiba 9000, BP 382, Beja, Tunisia \\ Correspondence should be addressed to Olfa Lengliz; olfalenglizridene@gmail.com
}

Received 24 October 2017; Accepted 14 December 2017; Published 8 January 2018

Academic Editor: Maria Roca

Copyright (c) 2018 Olfa Lengliz et al. This is an open access article distributed under the Creative Commons Attribution License, which permits unrestricted use, distribution, and reproduction in any medium, provided the original work is properly cited.

\begin{abstract}
The main concern of this work was to find a new biological antisprouting product for potatoes during storage. Ruta chalepensis L. essential oil (RCEO) was for the first time used as a potential sprouting inhibitor for potatoes. To confirm RCEO antisprouting effect, evolution of sprout length and weight loss of potato tubers was determined during a storage period of six weeks under three RCEO different treatments $(2 \%, 4 \%$, and $6 \%)$. Sprout final weight was also computed. Then, a screening of RCEO chemical composition was performed. An outstanding antisprouting effect of $6 \%$ emulsions concentrations was observed as compared to $2 \%$ and $4 \%$ emulsions concentrations. Final sprout weight (SW) of untreated samples was $4.66 \%$, while $6 \%$ treated samples scored $0.98 \%$. These results were endorsed by high Pearson correlation coefficients $(>0.9)$. Indeed, increasing treatment concentration enhanced the sprout growth inhibition. Identification of RCEO major components showed that 2-undecanone represented $87.18 \%$ of total identified components suggesting that this component is the possible active agent of RCEO against potatoes sprouting.
\end{abstract}

\section{Introduction}

Potato (Solanum tuberosum L.) ranks as the world's fourth most important food crop, after maize, wheat, and rice [1]. Being the world's number one nongrain food commodity, a great consideration should be attributed to its conservation. Potato tubers are usually stored for several months at a low temperature prior to planting to delay sprouting [2]. However, when dormancy is broken and sprouting is activated [3], important economic damage is recorded.

Therefore, effective sprout control is a major component of managing stored potato quality [4]. By far, the mostused chemical sprout inhibitor worldwide is chlorpropham (isopropyl-(N-3-chlorophenyl) carbamate (CIPC), CAS \# 101-221-3) [5]. However, it can negatively impact the environment and human health [6]. Therefore, safety considerations have prompted the EU to introduce both restrictions on application as well as maximum residue levels (mass of CIPC per mass of potato $0.063 \mathrm{gkg}^{-1}$ and $0.01 \mathrm{gkg}^{-1}$, resp.) [7].
Ethylene is also an effective potato sprout inhibitor, but it often darkens fry colour [8].

Nowadays, it is very important to use natural products compounds such as essential oils as well as the pure compound derived from essential oils [9]. Bioconservation could be a good alternative for potatoes quality preservation during storage without further environmental damage caused by the use of agrochemicals. Indeed, several essential oils have been identified with a sprouting inhibition potential on potatoes: the caraway (Carum carvi L.) essential oil [10, 11], the coriander (Coriandrum sativum L.) essential oil [12], and the mint (Mentha spicata L.) essential oil [6]. However, until now no previous studies were focused on the RCEO sprouting potential inhibition on potatoes. As a matter of fact, Ruta chalepensis L. is a wild plant widespread in the Mediterranean region [13] known mainly for its abortifacient, anthelmintic, antispasmodic, phytotoxic, antimicrobial, and antioxidant activities [14-19]. Yet, no data was found on potatoes bioconservation using Ruta chalepensis L. essential oil. 
Thus, the main purpose of the present work was to identify RCEO as a novel antisprouting agent for potatoes to substitute the existing agrochemical products for regeneration inhibition during storage. In fact, several sprout inhibition assays were performed to optimize RCEO emulsions concentrations to provide a pioneering potatoes bioconservator. Then, RCEO antisprouting components were identified using gas chromatography coupled to mass spectrometry.

\section{Material and Methods}

\subsection{Plant Material}

2.1.1. Tuber Material. Tuber material used in this study was Spunta potato variety. This cultivar represented the current Tunisian potatoes market (widely cultivated). Samples were collected during the summer of 2015 (June) and then stored in the Technical Center of Potato and Artichoke in Manouba, Tunisia.

2.1.2. Ruta chalepensis Material. Aerial parts of Ruta chalepensis were collected from El Fahs region, located at the north of Tunisia, during May and June 2015 at flowering stage.

2.1.3. Ruta chalepensis Essential Oil. RCEO was extracted from the aerial parts by hydrodistillation for $120 \mathrm{~min}$ using a clevenger apparatus type. Then, the obtained essential oil was stored at $4^{\circ} \mathrm{C}$ as previously described by Mejri et al. [20].

2.2. Sprout Inhibition Assays. RCEO emulsions (2\%, $4 \%$, and $6 \%)$ were prepared in sterilized water and Empicol ESB 70 as surfactant $(2.5 \%)$. A control treatment was applied by preparing an emulsion of sterilized water and Empicol ESB 70 (2.5\%) without essential oil.

Three boxes containing 10 potatoes were arranged for each treatment. Samples were immerged for $1 \mathrm{~min}$ in the emulsion for each concentration separately. Inhibition of potato sprouting assay was carried out during 6 weeks. Potato samples were kept in the darkness at $25^{\circ} \mathrm{C}$ to simulate traditional storage conditions.

\subsection{Tuber Storage Quality Parameters}

2.3.1. Sprout Length. Sprout length was measured weekly for each sample of each treatment.

2.3.2. Weight Loss. Sprouted potato samples were weighted each week for each treatment. Moreover, sprouts were separated from the potato tubers and weighted separately only for the last week.

Percentage of total weight loss (TWL), percentage of physiological weight loss (PhWL), and percentage of sprouts weight (SW) were computed using

$\mathrm{TWL}=100$

$$
\times \frac{\text { (initial weight }- \text { weight at week } 6 \text { with out sprouts) }}{\text { (initial weight) }}
$$

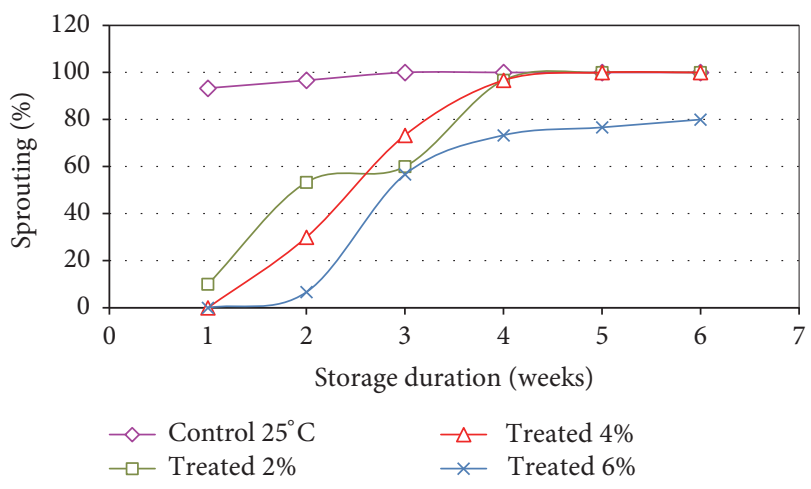

FIGURE 1: Effect of RCEO on potato sprouts length during storage: evolution of percentage of sprouting during storage at different treatments.

$$
\begin{aligned}
& \mathrm{PhWL}=100 \times \frac{(\text { initial weight }- \text { weight at week } X)}{(\text { initial weight })} \\
& \mathrm{SW}=100 \times \frac{(\text { sprouts weight })}{(\text { initial weight })} .
\end{aligned}
$$

PhWL illustrates the weight loss due to breathing and sweating. SW evaluates the loss due to sprouting. TWL is the sum of PhWL and SW.

2.4. Determination of Ruta chalepensis Essential Oil Bioactive Components. RCEO composition was determined using gas chromatography coupled to mass spectrometry (GC-MS) using a mass spectrometer HP 5975 C (Agilent Technologies) with electron impact ionization $(70 \mathrm{eV})$. A capillary column HP-5 ms was used $(30 \mathrm{~m} \times 250$ um coated with $5 \%$ phenyl methyl silicone, 95\% dimethyl polysiloxane, and the film thickness $0.25 \mathrm{um})$. The oven temperature was programmed from 60 to $220^{\circ} \mathrm{C}$ at a rate of $4^{\circ} \mathrm{Cmin}^{-1}$, and the tempering temperature was $230^{\circ} \mathrm{C}$. The carrier gas was helium with a flow rate of $0.8 \mathrm{mlmin}^{-1}$ and a split ratio of $50: 1$. Scanning time and range mass were $1 \mathrm{~s}$ and $50-550 \mathrm{~m} / \mathrm{z}$ (molecular mass/charge), respectively. RCEO components identification was performed by comparing their retention indices (RI) with corresponding data of commercial available standards.

2.5. Data Analysis. Standard one-way analysis of variance (ANOVA) was conducted to assess the effect of RCEO emulsions on potato sprout inhibition and weight loss using Duncan test. Pearson's correlation test was performed between parameters. All statistical tests were performed using the software SPSS version 13.0 (SPSS, Chicago, USA).

\section{Result and Discussions}

3.1. Effect of Ruta chalepensis L. Essential Oil on Potato Sprouts Length during Storage. Sprouting experiments were conducted during a storage period of six weeks using three different treatments (concentrations of emulsions). Figure 1 presents sprouting percentage evolution during potatoes storage. An overall assessment of sprouting evolution curves showed 


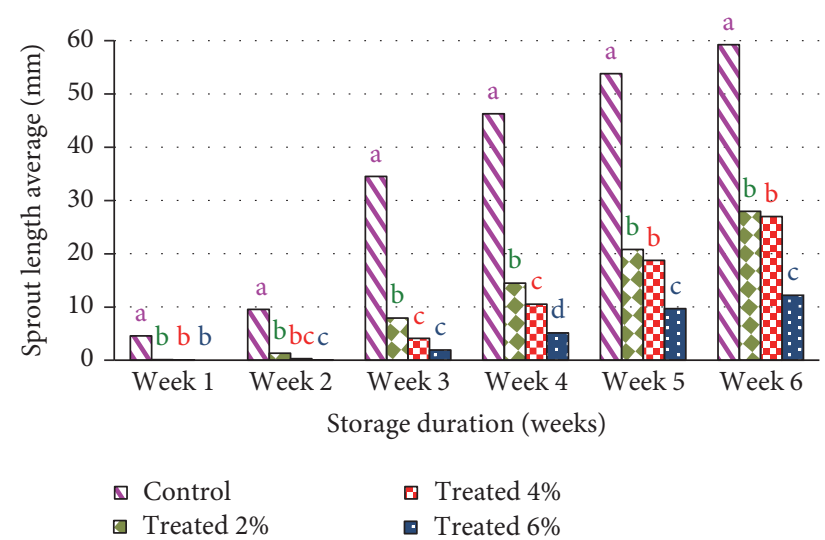

FIGURE 2: Effect of RCEO on potato sprouts length during storage. $(a, b, c)$ Data (for the effect of RCEO on sprout length for each week) with different letters are significantly different $(p \leq 0.001)$.

significant differences between the curves shapes suggesting significant differences between the studied samples interaction mechanism with the different treatments. Regarding treated samples, sprouting percentage increased smoothly to reach their maximum after four weeks of storage. In the case of samples treated by $6 \%$ emulsions, an apparent inhibitor effect on sprouting was observed since week 3 . In fact, notable difference was shown between treatment at $6 \%$ and the other treatments. However, less difference was detected between treatments at 2 and $4 \%$.

In order to investigate the impact of RCEO on sprouting, potatoes sprout lengths were statistically checked for each week under each treatment (Figure 2). ANOVA results revealed high significant differences between sprout length evolutions under the different treatments. In fact, different treatments of RCEO had significant effect ( $p \leq 0.05)$ on sprout inhibition. Untreated potato tubers began to sprout since the first week of storage, whereas the treated samples sprouting were irrelevant at this point. Remarkable difference in sprout length was found after two weeks of storage between the three different treatments, whereas treatment $6 \%$ was more efficient in inhibiting potato tubers sprouting. This result suggested that RCEO could be considered as possible alternative for sprouting inhibition. The sprout continued to grow after five weeks of storage under treated and untreated conditions, whereas Duncan's test showed no significant difference between treatments $2 \%$ and $4 \%$. After six weeks, sprout final length reached an average of $27.96 \mathrm{~mm}$, $26.96 \mathrm{~mm}$, and $12.2 \mathrm{~mm}$ under $2 \%, 4 \%$, and $6 \%$ treatments, respectively. As expected, the control sample recorded the highest final sprout length $(59.23 \mathrm{~mm})$. Furthermore, Duncan's test results confirmed that no relevant difference was detected between sprout length of potato tubers treated by $2 \%$ and $4 \%$ indicating the outstanding antisprouting effect of emulsions at $6 \%$. Indeed, by increasing the treatment concentration, the sprout growth was proven to be decreasing under the effect of essential oil.

These findings could be attributed to a direct effect of RCEO on cell division inducing sprout growth inhibition.

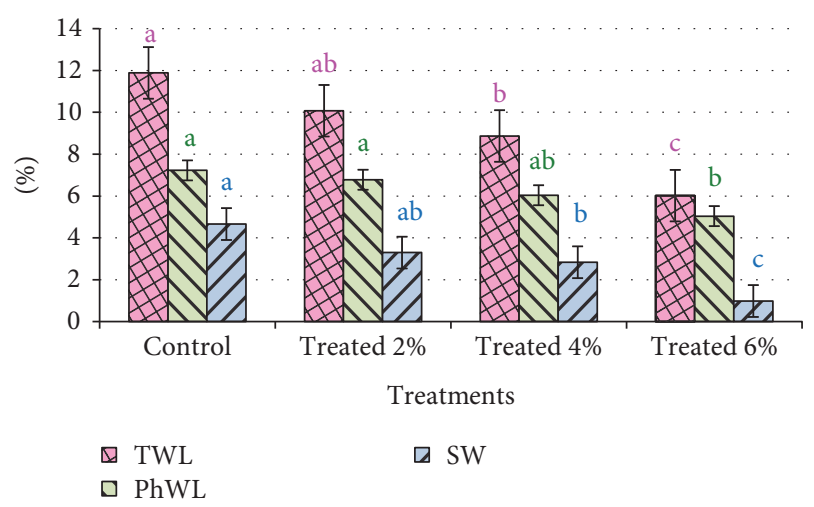

Figure 3: Effect of RCEO at different concentrations on weight loss of potato after 6 weeks of storage. TWL: total weight loss; PhWL: physiological weight loss; and SW: sprouts weight. (a, b, c) Data having different letters are significantly different $(p \leq 0.001)$ according to Duncan test results.

Romagni et al. findings established that essential oils and their components inhibit cell division in the root tips growth and interfere with DNA synthesis in growth meristem [21, 22]. However, Tworkoski et al. works indicated that essential oils inhibit plant growth by disrupting membrane integrity [23, 24]. Furthermore, other researches suggested that essential oils induce oxidative stress and inhibit root growth [2427]. In fact, essential oil improves lipid peroxidation and accumulation of hydrogen peroxide and increases the electrolyte leakage in root tissues [24, 27]. Moreover, Batish work showed that plants treated with essential oil of Eucalyptus showed significant degrees of ion leakage indicating a loss of membrane permeability leading to serious damage to the plant [28]. Furthermore, several studies [29-31] revealed that essential oils had a direct effect on the composition of chlorophyll and cell respiration.

3.2. Effect of Ruta chalepensis Essential Oil on Potato Weight Loss during Storage. Effect of RCEO treatments on potato weight loss was determined by weighing the tubers during storage period as presented in Figure 3.

Weight loss started effectively after two weeks of storage. In fact according to Fernie and Willmitzer, starch degradation is an important event related to the induction of sprouting [32]. Sprouting tuber needs to obtain energy from the mother tuber, which could cause weight loss. As matter of fact, significant difference between treatments was noticeable starting from week 3 as confirmed by ANOVA results. More particularly, Duncan's test revealed that until four weeks of storage, there was no significant difference between untreated and $2 \%$ treated samples $(\mathrm{PhW})$. Remarkably, samples treated with $4 \%$ and $6 \%$ emulsions reacted similarly until week 4 . However, only after five weeks of storage, a high significant difference was shown between $4 \%$ and $6 \%$ treatments. In fact, $4 \%$ treatment effect on tubers weight loss decreased, while it persisted for the treatment 6\% (Table 1). These findings suggested that the effect of RCEO on physiological weight loss started from the $4 \%$ concentration. Moreover, Figure 4 confirmed the great impact of $6 \%$ RCEO treatment 
TABLE 1: Evolution of the average of physiological weight loss during storage.

\begin{tabular}{lcccccc}
\hline Treatment & Week 1 & Week 2 & Week 3 & Week 4 & Week 5 & Week 6 \\
\hline Control & 0.7 & 1.4 & $2.9^{\mathrm{a}}$ & $4.3^{\mathrm{a}}$ & $5.7^{\mathrm{a}}$ & $7.2^{\mathrm{a}}$ \\
$2 \%$ & 0.8 & 1.4 & $1.4^{\mathrm{a}}$ & $3.9^{\mathrm{a}}$ & $5.3^{\mathrm{ab}}$ & $6.8^{\mathrm{a}}$ \\
$4 \%$ & 0.9 & 1.3 & $2.2^{\mathrm{b}}$ & $3.2^{\mathrm{b}}$ & $4.5^{\mathrm{bc}}$ & $6.0^{\mathrm{ab}}$ \\
$6 \%$ & 0.8 & 1.3 & $2.2^{\mathrm{b}}$ & $2.9^{\mathrm{b}}$ & $3.9^{\mathrm{c}}$ & $5.0^{\mathrm{b}}$ \\
\hline
\end{tabular}

Data are expressed as mean from three replicates. Means of the same column followed by different letters differ significantly $(p<0.001)$.

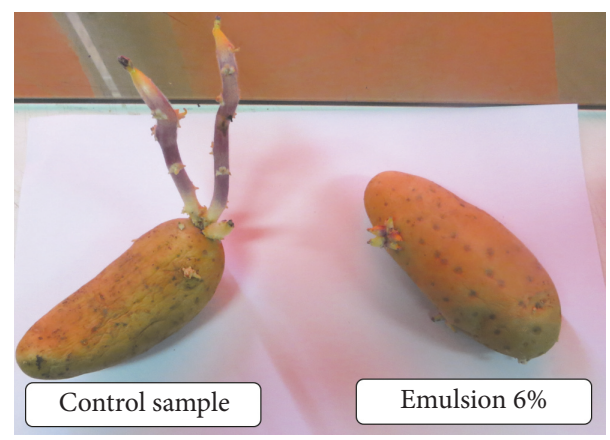

FIGURE 4: Effect of Ruta chalepensis essential oil on potato weight loss during storage: potatoes during the week 6 of storage: at the right, a potato treated with emulsion 6\%; at the left, control sample potato.

on sprouting. Indeed, we recorded a total weight loss of $11.88 \%$ for the control sample, while it was only $6.02 \%$ for the treatment $6 \%$, consistently with sprout weight assessment. In fact, untreated tubers final sprout weight was $4.66 \%$ of the initial weight, whereas for the treatment $6 \%$, it was $0.98 \%$. Furthermore, results showed that untreated samples scored a physiological weight loss of $7.22 \%$ of the initial tuber weight, while for the treatment 6\%, it was 5.04\% (Figure 3).

Thus, it could be concluded that sprouting inhibition probably delays tuber weight loss, as previously reported by Teper-Bamnolker et al. [6]. In fact, Pearson correlation coefficient results confirmed a high significant correlation between total weight loss and physiological weight loss (0.98), total weight loss and sprout final weight (0.99), and physiological weight loss and sprout final weight (0.94). These correlations could sustain the hypothesis indicating that RCEO affected the cell respiration, which could be the leading mechanism of the sprouting inhibition.

3.3. Ruta chalepensis Essential Oil Bioactive Components Identification. Active antisprouting agents of RCEO were analyzed by GC-MS. Table 2 presented the identified components in RCEO. Results showed that RCEO composition was rich in cetonic components $(95.17 \%)$, while $2.15 \%$ remained unidentified. The identified components were octane, 4isopropenyl-1-methyl-1-cyclohexene, 2-nonanone, nonanal, 1-methyl-5,6-divinyl-1-cyclohexene, 2-decanone, decanal, 2undecanone, 2-dodecanone, 2-tridecanone, 1-heptadecene, pentacosane, and 1,2-benzenedicarboxylic acid. Moreover, 2undecanone $(87.18 \%)$ was the main component of RCEO, consistently with previous findings [20, 33-35] $(68.95 \%$, $47.7 \%, 69.23 \%$, and $77.18 \%$, resp.). Chemical composition of
TABLE 2: Chemical composition of Ruta chalepensis L.essential oil.

\begin{tabular}{lccc}
\hline & KI & Rt & Proportion [\%] \\
\hline Octane & 791.3 & 3.2 & 0.7 \\
2-Nonanone & 1121.3 & 9.7 & 1.3 \\
Nonanal & 1134.5 & 10.1 & 0.9 \\
1-Methyl-5,6-divinyl-1-cyclohexene & 1177.5 & 11.4 & 0.2 \\
2-Decanone & 1231.1 & 13.0 & 5.1 \\
Decanal & 1245.3 & 13.4 & 0.2 \\
2-Undecanone & 1344.3 & 16.3 & $\mathbf{8 7 . 2}$ \\
2-Dodecanone & 1463.8 & 19.5 & 0.9 \\
2-Tridecanone & 1604.4 & 22.7 & 0.8 \\
1-Heptadecene & 1739.8 & 25.5 & 0.2 \\
Pentacosane & 1922.6 & 28.7 & 0.2 \\
1,2-Benzenedicarboxylic acid & 2172.1 & 32.9 & 0.2 \\
Unidentified components & & & 2.1 \\
\hline
\end{tabular}

KI: Kovat index; Rt: retention time.

the essential oil can be affected by climatic, seasonal, rainfall and geographic conditions, distillation technique, and harvest period [36].

RCEO was applied using three doses to enable a screening of treatments impact on sprouting level. Treatments recorded significant impact as antisprouting agent even at low doses. Therefore, the identification of RCEO active components could be considered as an important discovery. 2-Undecanone presented $87.18 \%$ of total identified components. So, we could assume that this component could be the possible active agent of RCEO. This antisprouting agent had a different action compared to chemical products. In fact, it is more correctly called sprout suppressants because they physically damage developing sprouts with a high concentration of the product in the surrounding headspace in the potato storage [4]. On the other hand, other potatoes antisprouting components in essential oils have been already identified in previous works. For instance, Bradow and Connick determined the effect of nine methyl ketones from Amaranthus palmeri S. Wats. (AMAPA) residues on seed germination of onion, carrot, AMAPA, and tomato [37]. In addition, R-carvone was the active sprouting inhibitor of mint essential oil during potatoes storage as previously reported by Teper-Bamnolker et al. [6].

\section{Conclusion}

The potential antisprouting effect of RCEO on potatoes during storage was investigated. Sprout length and weight loss 
of potato tubers curves as a function of storage duration (6 weeks) revealed high significant effect of the different treatments as confirmed by ANOVA results. A novel technique was successfully implemented to apply RCEO on potatoes with different emulsions concentrations. Tubers treated with $6 \%$ RCEO emulsions showed distinguished sprouting inhibition as compared to the other treatments, consistently with final sprouts measurements. Therefore, sprouting of potatoes during storage was associated with weight loss and sprout length as confirmed by high Pearson correlation coefficients $(>0.9)$.

RCEO composition screening revealed that 2-undecanone was the major component of RCEO (87.18\%) of the total identified components which could likely be the possible antisprouting agent of RCEO.

These findings suggested RCEO as a pioneering alternative for potatoes bioconservation without harmful drawbacks on environment. Further research is expected to confirm the 2-undecanone hypothesis as the RCEO active component.

\section{Conflicts of Interest}

The authors declare that there are no conflicts of interest regarding the publication of this paper.

\section{Acknowledgments}

The authors thank the Technical Center of Potato and Artichoke for participating in the realization of this work.

\section{References}

[1] FAOSTAT, Food and Agriculture Organization of the United Nations, Statistics Division. http://faostat3.fao.org/browse/rankings/commodities_by_regions/E, 2013.

[2] P. Delaplace, Y. Brostaux, M.-L. Fauconnier, and P. D. Jardin, "Potato (Solanum tuberosum L.) tuber physiological age index is a valid reference frame in postharvest ageing studies," Postharvest Biology and Technology, vol. 50, no. 1, pp. 103-106, 2008.

[3] W. K. Coleman, "Dormancy release in potato tubers: A review," American Journal of Potato Research, vol. 64, no. 2, pp. 57-68, 1987.

[4] M. J. Frazier, N. Olsen, and G. Kleinkopf, "Organic and alternative methods for potato sprout control in storage, CIS 1120," in University of Idaho, College of Agriculture and Life Sciences, Idaho, USA, 2004.

[5] B. J. Daniels-Lake, R. K. Prange, W. Kalt, and J. R. Walsh, "Methods to minimize the effect of ethylene sprout inhibitor on potato fry colour," Potato Research, vol. 49, no. 4, pp. 303-326, 2006.

[6] P. Teper-Bamnolker, N. Dudai, R. Fischer et al., "Mint essential oil can induce or inhibit potato sprouting by differential alteration of apical meristem," Planta, vol. 232, no. 1, pp. 179-186, 2010.

[7] O. Gouseti, A. Briddon, S. Saunders et al., "CIPC vapour for efficient sprout control at low application levels," Postharvest Biology and Technology, vol. 110, pp. 239-246, 2015.

[8] B. J. Daniels-Lake, K. Pruski, and R. K. Prange, "Using Ethylene Gas and Chlorpropham Potato Sprout Inhibitors Together," Potato Research, vol. 54, no. 3, pp. 223-236, 2011.
[9] A. El Awady, A. Moghazy, A. Gouda, and R. S. Elshatoury, "Inhibition of Sprout Growth and Increase Storability of Processing Potato by Antisprouting Agent," Trends in Horticultural Research, vol. 4, no. 2, pp. 31-40, 2014.

[10] K. J. Hartmans, P. Diepenhorst, W. Bakker, and L. G. M. Gorris, "The use of carvone in agriculture: sprout suppression of potatoes and antifungal activity against potato tuber and other plant diseases," Industrial Crops and Products, vol. 4, no. 1, pp. 3-13, 1995.

[11] K. Oosterhaven, B. Poolman, and E. J. Smid, "S-carvone as a natural potato sprout inhibiting, fungistatic and bacteristatic compound," Industrial Crops and Products, vol. 4, no. 1, pp. 2331, 1995.

[12] D. Gómez-Castillo, E. Cruz, A. Iguaz, C. Arroqui, and P. Vírseda, "Effects of essential oils on sprout suppression and quality of potato cultivars," Postharvest Biology and Technology, vol. 82, pp. 15-21, 2013.

[13] M. E. Gonzalez-Trujano, D. Carrera, R. Ventura-Martinez, E. Cedillo-Portugal, and A. Navarrete, "Neuropharmacological profile of an ethanol extract of Ruta chalepensis L. in mice," Journal of Ethnopharmacology, vol. 106, no. 1, pp. 129-135, 2006.

[14] L. C. Di Stasi, G. P. Oliveira, M. A. Carvalhaes et al., "Medicinal plants popularly used in the Brazilian Tropical Atlantic Forest," Fitoterapia, vol. 73, no. 1, pp. 69-91, 2002.

[15] E. B. Bnina, S. Hammami, M. Daami-Remadi et al., "Chemical composition and antimicrobial effects of Tunisian Ruta chalepensis L. essential oils," Journal de la Société Chimique de Tunisie, vol. 12, pp. 1-9, 2010.

[16] S. Ben Hadj Ahmed, R. M. Sghaier, F. Guesmi et al., "Evaluation of antileishmanial, cytotoxic and antioxidant activities of essential oils extracted from plants issued from the leishmaniasisendemic region of Sned (Tunisia)," Natural Product Research (Formerly Natural Product Letters), vol. 25, no. 12, pp. 1195-1201, 2011.

[17] N. Fakhfakh, S. Zouari, M. Zouari, C. Loussayef, and N. Zouari, "Chemical composition of volatile compounds and antioxidant activities of essential oil, aqueous and ethanol extracts of wild Tunisian Ruta chalepensis L (Rutacea)," Journal of Medicinal Plants Research, vol. 6, pp. 593-600, 2012.

[18] J. Mejri, J. Bouajila, S. B. Ali, M. Abderrabba, and M. Mejri, "Ruta chalepensis L. Essential Oil: chemical composition and phytotoxic activity," Journal of Biologically Active Products from Nature, vol. 2, no. 6, pp. 341-352, 2012.

[19] M. Kacem, I. Kacem, G. Simon et al., "Phytochemicals and biological activities of Ruta chalepensis L. growing in Tunisia," Food Bioscience, vol. 12, pp. 73-83, 2015.

[20] J. Mejri, M. Abderrabba, and M. Mejri, "Chemical composition of the essential oil of Ruta chalepensis L: influence of drying, hydro-distillation duration and plant parts," Industrial Crops and Products, vol. 32, no. 3, pp. 671-673, 2010.

[21] J. G. Romagni, S. N. Allen, and F. E. Dayan, "Allelopathic effects of volatile cineoles on two weedy plant species," Journal of Chemical Ecology, vol. 26, no. 1, pp. 303-313, 2000.

[22] N. Nishida, S. Tamotsu, N. Nagata, C. Saito, and A. Sakai, "Allelopathic effects of volatile monoterpenoids produced by Salvia leucophylla: Inhibition of cell proliferation and DNA synthesis in the root apical meristem of Brassica campestris seedlings," Journal of Chemical Ecology, vol. 31, no. 5, pp. 1187-1203, 2005.

[23] T. Tworkoski, "Herbicide effects of essential oils," Weed Science, vol. 50, no. 4, pp. 425-431, 2002.

[24] H. P. Singh, S. Kaur, S. Mittal, D. R. Batish, and R. K. Kohli, "Essential oil of Artemisia scoparia inhibits plant growth by 
generating reactive oxygen species and causing oxidative damage," Journal of Chemical Ecology, vol. 35, no. 2, pp. 154-162, 2009.

[25] L. R. Scrivanti, M. P. Zunino, and J. A. Zygadlo, "Tagetes minuta and Schinus areira essential oils as allelopathic agents," Biochemical Systematics and Ecology, vol. 31, no. 6, pp. 563-572, 2003.

[26] H. P. Singh, D. R. Batish, S. Kaur, K. Arora, and R. K. Kohli, “ $\alpha$ Pinene inhibits growth and induces oxidative stress in roots," Annals of Botany, vol. 98, no. 6, pp. 1261-1269, 2006.

[27] S. Mutlu, Ö. Atici, N. Esim, and E. Mete, "Essential oils of catmint (Nepeta meyeri Benth.) induce oxidative stress in early seedlings of various weed species," Acta Physiologiae Plantarum, vol. 33, no. 3, pp. 943-951, 2011.

[28] D. R. Batish, H. P. Singh, R. K. Kohli, and S. Kaur, "Eucalyptus essential oil as a natural pesticide," Forest Ecology and Management, vol. 256, no. 12, pp. 2166-2174, 2008.

[29] D. R. Batish, N. Setia, H. P. Singh, and R. K. Kohli, "Phytotoxicity of lemon-scented eucalypt oil and its potential use as a bioherbicide," Crop Protection, vol. 23, no. 8, pp. 1209-1214, 2005.

[30] S. Kaur, H. P. Singh, S. Mittal, D. R. Batish, and R. K. Kohli, "Phytotoxic effects of volatile oil from Artemisia scoparia against weeds and its possible use as a bioherbicide," Industrial Crops and Products, vol. 32, no. 1, pp. 54-61, 2010.

[31] T. Poonpaiboonpipat, U. Pangnakorn, U. Suvunnamek, M. Teerarak, P. Charoenying, and C. Laosinwattana, "Phytotoxic effects of essential oil from Cymbopogon citratus and its physiological mechanisms on barnyardgrass (Echinochloa crus-galli)," Industrial Crops and Products, vol. 41, no. 1, pp. 403-407, 2013.

[32] A. R. Fernie and L. Willmitzer, "Molecular and biochemical triggers of potato tuber development," Plant Physiology, vol. 127, no. 4, pp. 1459-1465, 2001.

[33] K. H. C. Baser, T. Özek, and S. H. Beis, "Constituents of the essential oil of ruta chalepensis L. from Turkey," Journal of Essential Oil Research, vol. 8, no. 4, pp. 413-414, 1996.

[34] G. D. Bagchi, P. D. Dwivedi, A. Singh, F. Haider, and A. A. Naqvi, "Variations in essential oil constituents at different growth stages of ruta chalepensis on cultivation at north indian plains," Journal of Essential Oil Research, vol. 15, no. 4, pp. 263-264, 2003.

[35] S. Merghache, M. Hamza, and B. Tabti, "Etude physicochimique de l'huile essentielle de Ruta chalepensis L. de Tlemcen, Algérie," Afrique Science: Revue Internationale des Sciences et Technologie, vol. 5, no. 1, pp. 67-81, 2010.

[36] J. Palá-Paúl, M. J. Pérez-Alonso, A. Velasco-Negueruela, R. PaláPaúl, J. Sanz, and F. Conejero, "Seasonal variation in chemical constituents of Santolina rosmarinifolia L. ssp. rosmarinifolia," Biochemical Systematics and Ecology, vol. 29, no. 7, pp. 663-672, 2001.

[37] J. M. Bradow and W. J. Connick Jr., "Volatile methyl ketone seed-germination inhibitors from Amaranthus palmeri S. Wats. Residues," Journal of Chemical Ecology, vol. 14, no. 7, pp. 16171631, 1988. 

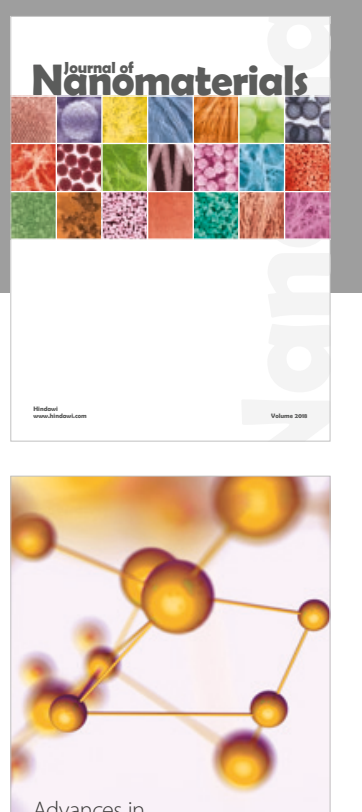

Physical Chemistry
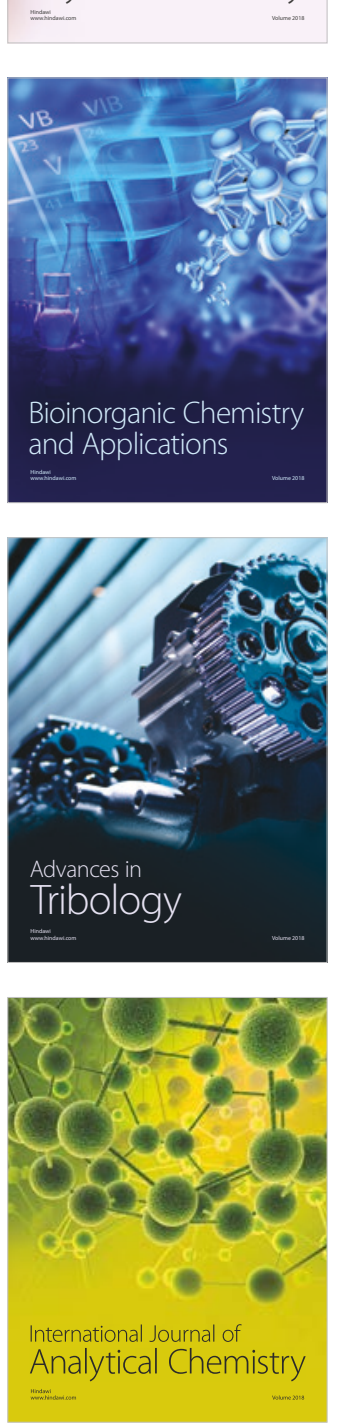

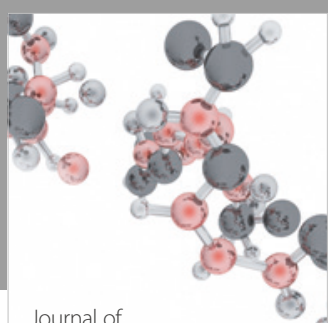

Analytical Methods

in Chemistry

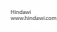

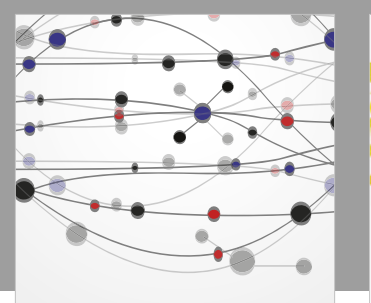

The Scientific World Journal

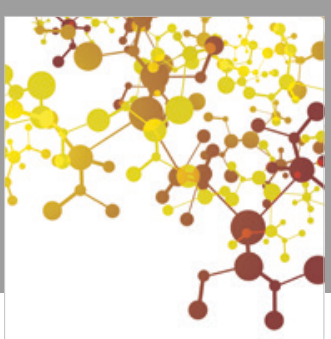

Journal of

Applied Chemistry
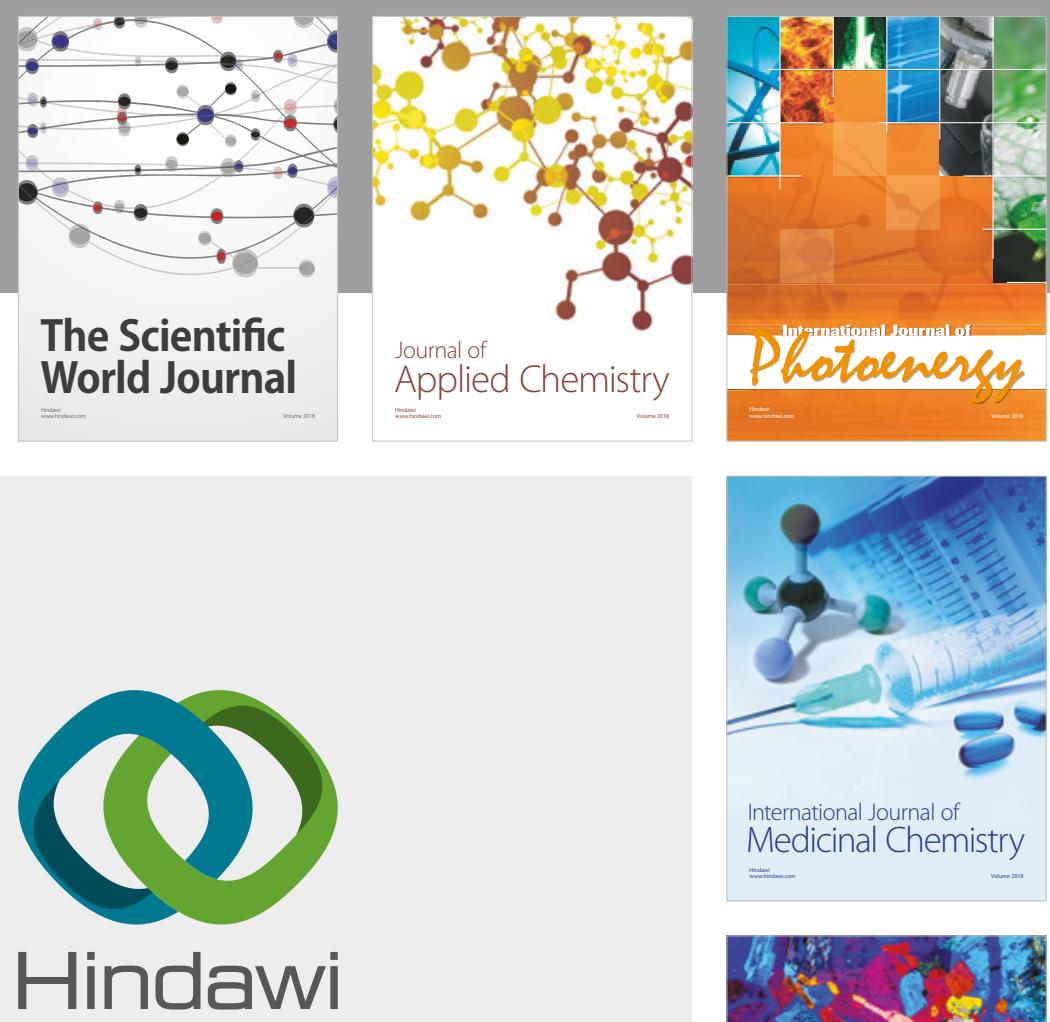

Submit your manuscripts at

www.hindawi.com
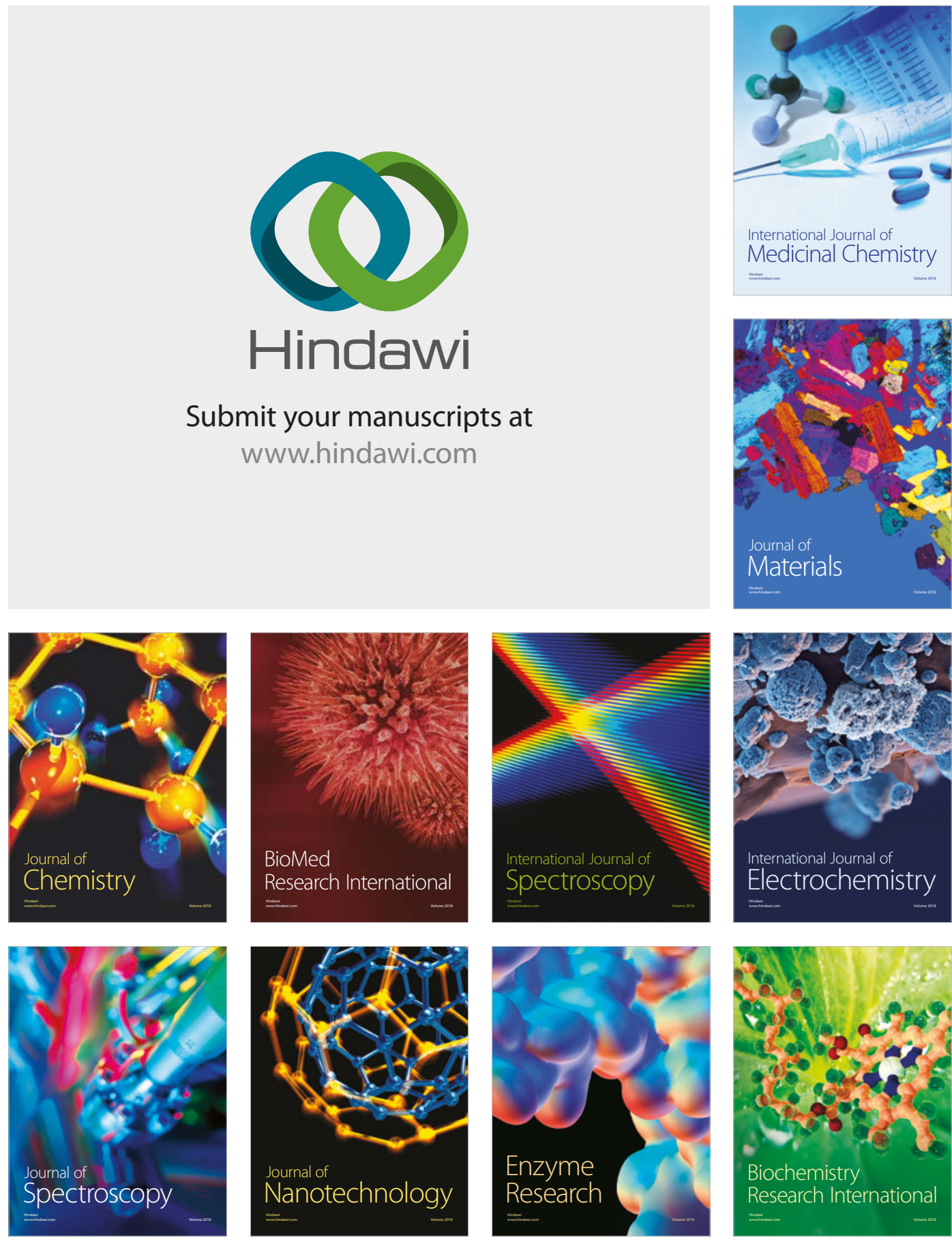
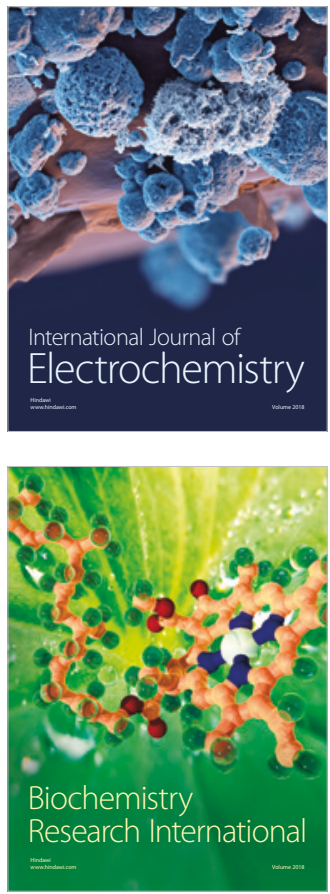